\title{
Atmospheric forcing of sulphate in speleothem carbonate
}

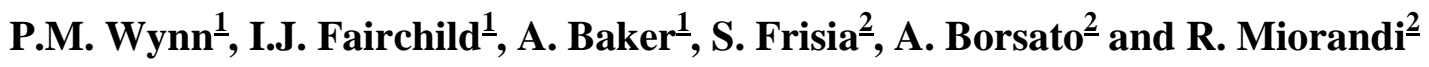 \\ ${ }^{1}$ School of Geography, Earth and Environmental Sciences, University of Birmingham, \\ Edgbaston, Birmingham B15 2TT, UK \\ ${ }^{2}$ Museo Tridentino di Scienze Naturali, Trento, Italy
}

Sulphur emitted into the atmosphere from anthropogenic combustion of fossil fuels has played a dramatic role in moderating climatic change. Trace amounts of sulphur in calcite speleothems suggest that stalagmites may act as archives of sulphur deposition, thereby recording aspects of atmospheric variability in sulphur content in mid-latitude locations.

Stalagmites obtained from a variety of sites with proportions of sulphur from different sources display concentrations ranging from 15 to $200 \mathrm{ppb}$ and trends in sulphur which either remain constant or show an increase over the past $\sim 150$ years. Due to the clear isotopic distinction between marine $(+21 \%)$, geological $(+10 \%$ o to $+30 \%)$, atmospheric pollution $(0-4 \%)$ and volcanic sources of sulphur (0-5\%), isotopic ratios provide a diagnostic tool with which changes in the source of atmospheric sulphur can be detected in a more reliable fashion than concentration alone. Initial results comparing $\delta^{34} \mathrm{~S}$ profiles from stalagmites in both coastal and pollution dominated locations have yielded isotope data identifying secular trends and accurately reflecting marine and anthropogenic sources of sulphur, respectively.

At Grotta di Ernesto cave, near the Dolomites in northern Italy, a rise in sulphur concentration from 15 to $65 \mathrm{ppm}$ in speleothem calcite is thought to reflect increasing anthropogenic pollution. $\delta^{34} \mathrm{~S}$ ratios are now being used to assess this assertion and determine how sulphur atmospheric inputs may be buffered by processes of storage, release and transformation within the overlying ecosystem prior to incorporation into speleothem calcite. Initial results show a clear isotopic distinction between host bedrock $(+17 \%$ o to $+21 \%$ ) and pollution dominated modern cave drip waters $(+1 \%$ to $+5 \%$ o $)$ and so we expect to see a strong secular trend whereby sulphur isotopic signatures depict increasing levels of pollution over the past $\sim 150$ years. An increase in both 
sulphur concentration and $\delta^{34} \mathrm{~S}$ values between input precipitation and cave drip waters, suggests the isotopic composition of sulphur available for incorporation into calcite is modified by the release of stored water as controlled by hydrological conditions. By determining site specific transfer functions, isotope ratios of sulphur within speleothems may be used successfully as an indicator of environmental and atmospheric change. 